\title{
Commensal Bacillus From Cow Milk Inhibits Staphylococcus Aureus Biofilm Formation and Mastitis in Mice
}

\section{Min Qiu}

Jilin university

Caijun Zhao

Jilin university

Lianjun Feng

Jilin University

Siyuan Gao

Jilin University

Xiaoyu Hu

Jilin University

Yunhe Fu ( $\square$ fuyunhesky@163.com )

Jilin University

Naisheng Zhang

Jilin university

\section{Research}

Keywords: S. aureus, biofilm, mastitis, quorum sensing, Bacillus subtilis

Posted Date: October 22nd, 2021

DOl: https://doi.org/10.21203/rs.3.rs-963658/v1

License: (c) (i) This work is licensed under a Creative Commons Attribution 4.0 International License. Read Full License 


\section{Abstract}

Background: Mastitis, one of the most serious diseases in dairy industry, could cause tremendous economic losses worldwide and is commonly trigged by pathogen invasion. Staphylococcus aureus ( $S$. aureus) induced mastitis has been reported to play an important role in mastitis etiology characterized by high morbidity, recurrence, and increased antibiotic resistance, which may attribute to the formation of biofilm formation, a form of bacterial aggregation for better growth and resistance to adverse conditions. Probiotics Bacillus has been reported to disrupt bacteria quorum-sensing (QS) system, a central regulator for biofilm formation. However, whether commensal Bacillus affects $S$. aureus biofilm formation and consequent colonization during mastitis is still unknown.

ResultsవHere, we identified that the Bacillus is associated with reduced colonization of S. aureus in the mammary gland of cows. Interestingly, Bacillus did not affect $S$. aureus growth but inhibited the biofilm formation of S. aureus by interfering with S. aureus QS signaling. The most obvious anti-biofilm effect was found in Bacillus subtilis $\mathrm{H} 28$, so it was selected for further study. We found that bacillus subtilis $\mathrm{H} 28$ treatment alleviated S. aureus-induced mastitis in mice, as showed by limiting pro-inflammatory cytokines production, enhancing barrier integrity, and reducing S. aureus burden. Consistently, Bacillus subtilis with the capacity to interfere S. aureus QS ameliorated S. aureus-induced NF-KB activation in mice mammary epithelial cells $₫$ MMECs $\rrbracket$.

Conclusions: Collectively, our results indicate that commensal Bacillus inhibits S. aureus colonization and alleviates $\mathrm{S}$. aureus-induced mastitis by influencing biofilm formation, which suggests a potential strategy for the decolonization of $\mathrm{S}$. aureus and acts as a basis for the prevention and treatment of $\mathrm{S}$. aureus-related disease.

\section{Introduction}

Mastitis is one of the most serious diseases in dairy cows, especially in high-yielding cows(1). The high incidence of mastitis and the difficulty of preventing and treating it has been one of the foremost diseases plaguing the health of the world's dairy industry (2). There is no effective vaccine for its prevention. Antibiotics are still the only means of clinical prevention and treatment of $S$. aureus (3). However, the non-standard use of antibiotics makes the drug increasingly serious resistant to $S$. aureus for a long time (4). In addition to improper production management and drug use, the complex biological functions of $S$. aureus also increase its bacterial resistance. It is reported that $S$. aureus has a strong biofilm-forming ability that was found to be significantly related to the severity of the disease (5). Much of the colonization and virulence production of $S$. aureus depends on its population sensing system (QS) and biofilm formation, and the microbial biofilm is responsible for the persistence of $S$. aureusrelated disease (6). Therefore, difficulty of mastitis control induced by $S$. aureus may be related to the long-term colonization of the mammary site by $S$. aureus. 
Biofilm is a kind of growth corresponding to planktonic bacteria in which bacteria adsorb to the surface of inert or active entities during the growth process to adapt to their living environment (7). S. aureus has a QS system, which is a central regulator in $S$. aureus pathogenicity (8). It can regulate adhesion and production of numerous virulence and pathogenic factors as well as the biofilm formation and heterogeneous resistance of $S$. aureus (9). The bacterial QS system is an intercellular communication mechanism used to synthesize, secrete and detect small signaling molecules to sense bacterial population densities and regulate the expression of specific genes in response to environmental changes (10). The QS system allows bacteria to function as multicellular organisms because the concentration of extracellular self-inducers increases as the number of bacteria grows. After reaching a certain amount, this molecule diffuses back into the bacteria and regulates the transcription of different genes related to biofilm secretion and other (11). The QS system is important in order to bacterial biofilm formation. Therefore, this QS system is a paramount target for the treatment of microbial biofilm associated infections (12). Once formed, biofilms protect bacteria from the action of traditional antibacterial drugs and exhibit multi-drug resistance, leading to the ineffectiveness of long-term antibiotic therapy (13). The biofilm also protects the bacteria from the immune response of the body and enables them to survive in a harsh environment(14). Therefore, the biofilm of $S$. aureus is considered an essential pathogenic feature.

Previous studies have found that live probiotic microorganisms are present in healthy milk, which considered to be the presence of self- or commensal microbiota. As one of the normal host microbiotas, Bacillus also is available in the mammary gland of cows (15). Different Bacillus strains showed antibacterial, antioxidant, and immunomodulatory activities in their hosts (16). Recently, probiotics such as bacillus have been utilized to prevent infection, because it is a nonpathogenic Gram-positive bacterium that can availably maintain a beneficial microflora balance in the gastrointestinal tract of a mammalian host (17). B. subtilis-fermented fermentation products can promote the growth performance of immunestressed broilers and regulate the composition of intestinal microflora (18). In addition, the exclusion of pathogens by inhibition of bacterial biofilms is another potential property of the proposed Bacillus strain (19). Evidence accumulated from animal and in vitro studies indicates that $B$. subtilis yields a variety of substances, such as surfaceins, iturins and fengycins, which may contribute to antibacterial, antiinflammatory, and immunomodulatory applications $(17,18)$. Specifically, a recent report showed that the secreted substance from $B$. subtilis abolished colonization with $S$. aureus by suppressing the production of the Arg-quorum-sensing signaling system (17). However, whether $B$. subtilis can reduce the colonization of mammary glands by $S$. aureus has not been reported.

Therefore, we hypothesized that there is interference between the mammary symbiotic bacterium Bacillus and the pathogenic bacterium S. aureus. Bacillus can reduce the colonization of $S$. aureus and thus relieve $S$. aureus-induced mastitis. Here, we found that Bacillus eliminated the colonization of the dangerous pathogen $S$. aureus in the mammary gland of cows. Further studies revealed that Bacillus disrupts the formation of biofilm and thus reduces the colonization of $S$. aureus probably by affecting the QS system of $S$. aureus. Using mice mastitis model, we also demonstrated that Bacillus ameliorated $S$. aureus-induced mastitis, as showed by improving mammary injury, limiting inflammatory markers, and promoting blood-milk barrier integrity. Collectively, our findings that bacillus with the capacity to eliminate 
mammary gland pathogen colonization through disrupting biofilm formation protects against $S$. aureuse induced mastitis in mice, suggests that probiotics that interfere with the formation of pathogenic biofilms may serve as a potential and effective st rategy to protect mastitis S. aureus-related disease.

\section{Materials And Methods}

\section{Materials}

TNF- $\alpha$ and IL-1 $\beta$ ELISA kits were purchased from Biolegend (CA, USA). Tissue protein extract and BCA Protein Assay Kit were bought from Thermo (Thermo, MA, USA). Trypticase Soy Broth (TSB) and bacillus medium were purchased from Qingdao Haibo Biotechnology Co., Ltd (Qingdao, China). Crystal Violet Stain solution, $1 \%$ was acquired from Solarbio (Solarbio, Beijing, China). All the monoclonal antibodies, including $\beta$-actin, p65, ІкB, the phosphorylation of p65, phosphorylation IKB, ZO-1, Occludin, and Claudin-

3 were recruited from Cell Signaling Technology (Beverly, MA, USA). MPO kit was available from Nanjing Jiancheng Co., Ltd (Nanjing, China).

\section{Animals}

A total of $60 \mathrm{Balb} / \mathrm{c}$ mice (40 females and 20 males) aged 6-8 weeks were purchased from the Liaoning Changsheng Biotechnology Co. Ltd. The animal experiments were subject to approval by the Animal Ethics Committee of Jilin University (KT202103058). Females and males are mixed in miniature isolation cages in about a ratio of 2 to 1 after adapting to the environment with free food and water. The mastitis model was established complying with the experimental animal manual. This study is built on the Handbook on the Care and use of Experimental Animals published by the National Institutes of Health.

\section{Bacteria and culture conditions}

Bacillus were isolated from healthy and mastitis milk samples from dairy cows in Baicheng, Jilin Province), ChiFeng, Inner Mongolia, and Weifang, Shandong Province, China. A total of 145 strains of Bacillus bacteria were separated and purified by the specific culture of bacillus medium plate. $S$. aureus (ATCC 35556) was acquired from American Type Culture Collection. In the present study, S. aureus was inoculated for about 6 hours at the condition of $37^{\circ} \mathrm{C}$ and $120 \mathrm{r} / \mathrm{min}$, and the OD 600 was about 0.5 (concentration was approximately $10^{8} \mathrm{CFU} / \mathrm{mL}$ ). Meanwhile, $B$. subtilis bacteria were inoculated into the TSB broth medium by the same inoculation method, and then the OD 600 reached about 0.6 (concentration was approximately $10^{8} \mathrm{CFU} / \mathrm{mL}$ ) after 4 hours of growth.

\section{Preparation of cell-free supernatant (CFS) from Bacillus culture and treatments}

To prepare Bacillus CFS, Bacillus strains were cultured at $37^{\circ} \mathrm{C}$ under shaking at $200 \mathrm{rpm}$ overnight until the cultures reached an OD 600 of $0.6 \pm 0.05$. The CFS of bacterial culture was collected by centrifugation at $6000 \mathrm{~g}$ for $10 \mathrm{~min}$, and then filtered through a $0.22 \mu \mathrm{m}$ sterilizing-grade filter (Millipore, SLGV033RB, USA) to remove bacteria. To evaluate the effect of Bacillus CFS on $S$. aureus genes expression, overnight culture of $S$. aureus strains was collected by a centrifuge, washed with PBS, re-suspended at $10^{8} \mathrm{CFU} / \mathrm{mL}$ 
in TSB/PBS $\left(1: 1 \mathrm{v} / \mathrm{v}\right.$, control) or TSB/B. subtilis CFS $(1: 1 \mathrm{v} / \mathrm{v})$ and incubated in 6-well-plate at $37^{\circ} \mathrm{C}$ for 3 h. Finally, bacteria were collected for RNA extraction and analysis of genes expression.

\section{Antibacterial experiment.}

To determine the antibacterial effect of $B$. subtilis CFS on $S$. aureus, the Bacillus supernatant was obtained using the method described previously (18). Briefly, the supernatant of Bacillus bacteria was added into 96 -well plates. $10 \mu \mathrm{L}$ of $S$. aureus suspension $\left(5 \times 10^{8} \mathrm{CFU} / \mathrm{mL}\right)$ from a fresh overnight culture was inoculated into $200 \mu \mathrm{L}$ TBS (control), Bacillus CFS, TSB/ Bacillus CFS (1:1 v/v) or TSB/ Bacillus CFS $(0.5: 1.5 \mathrm{v} / \mathrm{v})$ and incubated at $37^{\circ} \mathrm{C}$ or $24 \mathrm{~h}$. The growth of $S$. aureus was determined by monitoring OD 600 of the cell culture.

\section{Biofilm formation and viability assay}

To evaluate the effect of Bacillus CFS on S. aureus biofilm formation, $10 \mu \mathrm{L}$ of $S$. aureus $\left(5 \times 10^{8}\right.$ $\mathrm{CFU} / \mathrm{mL}$ ) was added to $200 \mu \mathrm{L}$ of TSB (control) or TSB/ Bacillus CFS $(1: 1 \mathrm{v} / \mathrm{v})$ in each well on a 96-well plate and incubated at $37^{\circ} \mathrm{C}$ for indicated time points without shaking. Next, the wells were washed three times with sterile PBS after the medium was removed. Finally, the plates were air-dried for 45 min and the adherent cells and matrix were stained with $1 \%$ crystal violet solution. To quantify the biofilm production, crystal violet was extracted by incubation in a solution ( $95 \%$ ethanol) at room temperature for $15 \mathrm{~min}$, and absorbance was measured at $570 \mathrm{~nm}$ in a microplate reader.

\section{RNA extraction and Quantitative real-time PCR (QRT-PCR)}

Total RNA of S. aureus was extracted with a Bacterial RNA Extraction Kit (B518655-0050, Sangon Biotech, Shanghai, China) following the manufacturer's instructions. RNA purity was verified using a NanoDrop spectrophotometer (ND-1000, Nanodrop, USA). RNA was reversely transcribed using the 5x Prime Script RT Master Mix (RR036A, Takara, Shiga, Japan) according to the manufacturer's instructions. QRT-PCR was carried out using TB Green Premix Ex Taq II (RR820A, Takara, Shiga, Japan). Fold changes in level of chosing genes expression were determined using the $2^{-\Delta \Delta C t}$ method.

\section{Animal treatment and mastitis model}

Totally forty female Balb/c mice 5-7 days after delivery were randomly divided into four groups: control group, S. aureus group ( $1 \times 10^{8} \mathrm{CFU}$ per $100 \mu \mathrm{L}$ PBS $)$, B. subtilis H28 group $\left(1 \times 10^{8} \mathrm{CFU}\right.$ per $100 \mu \mathrm{L}$ PBS), B. subtilis H28 $\left(1 \times 10^{8} \mathrm{CFU}\right.$ per $100 \mu \mathrm{L}$ PBS $)+S$. aureus $\left(1 \times 10^{8} \mathrm{CFU}\right.$ per $100 \mu \mathrm{L}$ PBS $)$ group. For induction of mastitis, $S$. aureus $\left(1 \times 10^{8} \mathrm{CFU}\right.$ per $50 \mu \mathrm{L}$ PBS $)$ was an injected into each mammary gland of the mice using $100 \mu \mathrm{L}$ syringes with a 30 gauge blunt needle. In the $B$. subtilis $H 28$ group, the mammary gland of mice received an injection dose of intramammary with $B$. subtilis $H 28\left(1 \times 10^{8} \mathrm{CFU}\right.$ per $100 \mu \mathrm{L}$ PBS), later 2 hours $S$. aureus was an injected into each mammary gland. The control group mice received an injection dose of intramammary with an equal volume of sterile PBS. Twenty-four hours 
later, the mice were sacrificed and the mammary gland tissues were harvested and stored at $-80^{\circ} \mathrm{C}$ for subsequent detection.

\section{Histological analysis}

24 hours after $S$. aureus infection, the mammary gland tissues of each group were collected and fixed in $4 \%$ paraformaldehyde for $48 \mathrm{~h}$. The sample was inserted into paraffin and cut into $4 \mu \mathrm{m}$ sections. After deparaffinization, the sections were stained with hematoxylin and eosin (H\&E), and histological analysis was conducted under an optical microscope. The main histopathological indicators are through hyperemia (grade 0-3, ranging from normal to severe, including normal, mild, moderate, and severe) and neutrophil infiltration (grade $0-5$, grade 0 , from nothing to transmural) to evaluate.

\section{MPO activity assay}

MPO activity is a functional and activation marker of neutrophils. The mammary gland tissue was harvested and homogenized on ice with reaction buffer (weight/volume ratio 1:19). The detection method of MPO activity was carried out according to the manufacturer's instructions (Nanjing Jiancheng Institute of Bioengineering, Nanjing, China).

\section{ELISA assay}

The inflammatory cytokine was established using an ELISA kit, according to the manufacturer's instructions. $10 \%$ tissue homogenate was prepared and centrifuged at $4^{\circ} \mathrm{C}, 12000 \mathrm{r} / \mathrm{min}$, for $10 \mathrm{~min}$. The lipid layer was removed, and the middle supernatant was collected for detection. Use a microplate reader to test the read absorbance of the sample at $450 \mathrm{~nm}$ and $570 \mathrm{~nm}$.

\section{Mammary S. aureus load assay}

To assess the $S$. aureus burden in the mammary gland, mammary tissues were aseptically obtained in mice and homogenized in $1 \mathrm{~mL}$ of PBS. A 10-fold dilution of the tissue homogenate was plated in mannitol high salt agar plates. Bacterial colonies were counted and calculated following plate incubation at $37^{\circ} \mathrm{C}$ for $18 \mathrm{~h}$. Results of bacterial burden were expressed on a log 10 scale.

\section{Western Blotting Analysis}

The BCA protein detection kit was utilized to detect the protein concentration in mammary gland tissues. The protein samples were separated by $10 \%$ SDS-PAGE, then protein samples were transferred to the PVDF membrane and blocked in 5\% skimmed milk at room temperature for $2 \mathrm{~h}$. Use primary antibodies $\beta$ actin (1:1000), phospho-IKB (1:1000), IKB (1:1000), NF-KB p65 (1:1000) ZO-1 (1:500) Occludin(1:1000) and Claudin-3 (1:1000)and phospho-NF-KB p65 (1:1000) in Incubate overnight at $4^{\circ} \mathrm{C}$. The membrane was washed three times with TBST for 10 minutes each time and incubated with goat anti-rabbit secondary antibody for $2 \mathrm{~h}$ at room temperature. Finally, use of the ECL Plus Western blotting detection system to detect the cell membrane. 


\section{Immunohistochemistry (IHC)}

The paraffin-embedded glass slides were dewaxed in xylene and different concentrations of alcohol. The antigen is restored with $0.01 \mathrm{M}$ citrate buffer. Incubate in $3 \% \mathrm{H}_{2} \mathrm{O}_{2}$ and then in diluted goat serum. The sections were incubated with primary antibodies: Claudin $3(1: 500)$ at $4^{\circ} \mathrm{C}$. After washing 3 times, the sections were incubated with HRP-labeled goats with anti-rabbit secondary antibody (1:500, ZS-Bio, Beijing, China) at $37^{\circ} \mathrm{C}$ for $15 \mathrm{~min}$. This section was stained with $\mathrm{DAB}$ and observed under a microscope.

\section{Statistical analysis}

GraphPad Prism 5 (Manufacturer, La Jolla, CA, USA) was performed for statistical analysis. The data are presented as mean \pm SEM. $p<0.05$ indicated statistical significance by one-way ANOVA and Tukey's multiple comparisons test.

\section{Results}

Increased S. aureus colonization contributes to cow mastitis and is associated with reduced commensal Bacillus.

To investigate the correlation between S. aureus and Bacillus colonization in the mammary gland, we performed the culture-based analysis of milk samples with swabs taken from healthy non-mastitis cows and mastitis cows. The absolute abundance of total S. aureus and Bacillus on milk swabs was evaluated by manual colony counting for colony-forming units (CFUs) on a selective egg yolk mannitol salt agar and Bacillus culture medium respectively. As showed in Fig. 1A, we can clearly observe substantial differences in the quantity of $S$. aureus between health and mastitis cows that more colonization of $S$. aureus in mastitis cows. Meantime, we found that healthy cow had more Bacillus colonization than mastitis cows (Fig. 1B). Previous studies have found that laboratory isolates of Bacillus species can reduce the colonization of $S$. aureus (19). One explanation for the larger amount of $S$. aureus from mastitis milk compared to normal milk was that Bacillus from normal milk may affect colonization of $S$. aureus. Therefore, we next sought to further determine whether was a correlation between Bacillus and $S$. aureus. We started raising a striking correlation between the presence of Bacillus bacteria and the absence of $S$. aureus. We first assessed the effect of the presence or absence of $S$. aureus colonization on the number of Bacillus. The results showed in that the number of Bacillus decreased in the presence of $S$. aureus colonization in both health and mastitis cows (Fig. 1C). We then analyzed the effect of Bacillus on $S$. aureus colonization and found that lower load of $S$. aureus was detected in healthy and mastitis cows when Bacillus was colonized (Fig. 1D). These results are mentioned that there is a negative correlation between $S$. aureus and Bacillus in the milk.

Commensal Bacillus inhibits $\mathrm{S}$. aureus colonization through affecting the biofilm formation of $\mathrm{S}$. aureus.

It has been declared in the literature that Bacillus can inhibit the population sensing system of $S$. aureus, thus reducing the colonization of the intestinal tract by $S$. aureus (18). We therefore hypothesize that 
Bacillus may exert a broad mechanism for comprehensively inhibit $S$. aureus colonization in the mammary gland. In the results of the flow disease survey, it was shown that the presence of Bacillus in the mammary gland could be a possibility determining factor for the absence of $S$. aureus in cows. We first analyzed whether there is a growth-inhibitory effect of the Bacillus isolates on $S$. aureus. To detect antimicrobial growth effect, we randomly isolated about 145 individual Bacillus isolates from the milk samples and then conducted an unbiased analysis of antimicrobial activity by determining the capacity of the sterile conditioned supernatant of each individual isolate to inhibit $S$. aureus growth. However, we found no difference in the antibacterial effect between S. aureus-negative and -positive Bacillus (Fig. 2A). Therefore, a growth-inhibitory effect not is able to explain the observed complete correlation between the presence of Bacillus and the absence of $S$. aureus, and rules out a bacteriocin-mediated phenomenon. The factors that are important in order to $S$. aureus mammary colonization are poorly understood. A previous study has implicated that quorum-sensing (QS) is a requirement for $S$. aureus to colonize the intestine, and discovering that secreted Bacillus function as QS blockers to achieve complete eradication of intestinal $S$. aureus (19). We then examined the anti-S. aureus biofilm capacity of $S$. aureus-negative and -positive Bacillus and found that $S$. aureus-negative Bacillus had higher anti-S. aureus biofilm capacity than S. aureus-positive Bacillus (Fig. 2B). We next determined the ability of biofilm formation between health and mastitis cow isolated $S$. aureus and showed that $S$. aureus from mastitis cow had higher biofilm formation capacity than $S$. aureus from non-mastitis. Collectively, these results suggest that Bacillus inhibits $S$. aureus colonization by affecting the biofilm formation of $\mathrm{S}$. aureus.

\section{Bacillus inhibits $\mathrm{S}$. aureus biofilm formation by regulating QS signaling.}

To detect anti-biofilm activity, we randomly isolated about 145 individual Bacillus isolates from each milk culture swab and then conducted an unbiased analysis of anti-biofilml activity by measuring the capacity of the sterile conditioned supernatant of each individual isolate to inhibit S. aureus biofilm (Fig. 2A). The showed that the anti-biofilm effect of different Bacillus species varied significantly, and we performed the strain with the best anti-biofilm effect for an intensive investigation which was identified by 16S RNA sequencing and was named as Bacillus subtilis H28 (B. subtilis H28) (Fig. 3B). As shown in Fig. 3C, B. subtilis $\mathrm{H} 28$ strain did not produce any inhibition loop on agar. Moreover, biofilm formation in static $S$. aureus culture was evaluated by crystal violet staining. Results showed much faint staining in the culture of $B$. subtilis $\mathrm{H} 28$ treated S. aureus (Fig. 3D), which was significantly different from the group with the addition of $S$. aureus alone indicating that bacillus has an inhibitory effect on biofilm production of $S$. aureus. Moreover, we counted the $S$. aureus in the biofilm and showed that $B$. subtilis $\mathrm{H} 28$ significantly reduced the number of $S$. aureus in the biofilm (Fig. 3F).

To confirm whether the $B$. subtilis $\mathrm{H} 28$ supernatant had antibacterial activity, $5 \times 10^{8}$ CFUs of $S$. aureus were grown for $48 \mathrm{~h}$ in $25 \%, 50 \rrbracket$, and $100 \bigotimes$ supernatant of $B$. subtilis $\mathrm{H} 28$ in polystyrene plates for 2 days at $37^{\circ} \mathrm{C}$. As shown in Fig. $4 \mathrm{~A}$, different concentrations of $B$. subtilis $\mathrm{H} 28$ supernatant had no effect on bacterial growth. To test for the effects of $B$. subtilis $\mathrm{H} 28$ on biofilm formation in vitro, $\mathrm{S}$. aureus was treated as similarly and biofilm was stained with crystal violet and determined at OD $570 \mathrm{~nm}$. We found that $B$. subtilis $\mathrm{H} 28$ reduced cell attachment and biomass in a concentration-dependent manner (Fig. 4A). 
To test whether $B$. subtilis $\mathrm{H} 28$ has a disruptive effect on biofilms already formed in vitro, $5 \times 10^{8} \mathrm{~S}$. aureus cells were incubated in polystyrene plates at $37^{\circ} \mathrm{C}$ for 2 days. Afterwards, $25 \%, 50 \%$, and $100 \% B$. subtilis $\mathrm{H} 28$ supernatants were added and incubation was continued for $24 \mathrm{~h}$. We demonstrated that $B$. subtilis $\mathrm{H} 28$ inhibited the biofilm already formed in a dose-dependent manner (Fig. 4B). However, a noninhibitory bacillus cannot destroy the biofilm formed by S. aureus (Fig. 4B).

Biofilm formation involves the expression and regulation of multiple genes (20). The QS system controls $S$. aureus biofilm formation and release of virulence factors (21). Researchers have indicated that the accessory gene regulator (Agr) system regulates the QS system of $S$. aureus (22). S. aureus secretes the polysaccharide intercellular adhesion (PIA) is a factor necessary for the bacterial aggregation phase of its biofilm formation, and PIA synthesis is mainly encoded by the ica manipulator $(23,24)$. The RNAllI activating peptide is considered as an auto-inducible peptide that phosphocreeatine its target molecules, activates the Agr system, and regulates biofilm formation $(25,26)$. We then analyzed the effect of $B$. subtilis $\mathrm{H} 28$ on the expression of genes involved in population sensing (ArgA and RNA III) and biofilm formation gene ica. We showed that $B$. subtilis $\mathrm{H} 28$ treatment significantly down-regulated the mRNA expression of all the above genes (Fig. 4C-E). Taken together, these results indicate that Bacillus inhibited the biofilm formation of $S$. aureus by regulating the QS system.

\section{B. subtilis $\mathrm{H} 28$ protects against $\mathrm{S}$. aureus induced mastitis in mice}

We then investigated whether $B$. subtilis $\mathrm{H} 28$ could ameliorate $S$. aureus induced mastitis. The results showed that $S$. aureus infection resulted in observable pathological damage of the mammary gland, including edema, inflammatory cell infiltration, and disarrangement of the mammary gland structure (Fig. $5 A-B)$. However, pre-treatment with $B$. subtilis $\mathrm{H} 28$ significantly alleviated these pathological damages of the mammary gland induced by $S$. aureus (Fig. 5A-B). The mammary gland enumeration of bacterial burdens revealed that $S$. aureus mice harbored higher bacterial burdens, while $B$. subtilis $\mathrm{H} 28$ treatment did substantially reduce bacterial burdens in the mammary gland (Fig. 5C). S. aureus treated mice had higher MPO activity than control mice, while it was reduced by $B$. subtilis $\mathrm{H} 28$, and administration of $B$. subtilis $\mathrm{H} 28$ alone did not affect the MPO activity when compared with the control group (Fig. 5D). In addition, $B$. subtilis $\mathrm{H} 28$ inhibited the production of TNF-a and IL-1 $\beta$, the major pro-inflammatory cytokines in mastitis, induced by S. aureus (Fig. 5E-F).

\section{B. subtilis $\mathrm{H} 28$ improves the blood-milk integrity by increasing expressions of the tight junction proteins}

To assess the effect of $B$. subtilis $\mathrm{H} 28$ on $S$. aureus-induced damage of the epithelial barrier integrity, we examined the expression of ZO-1, Occludin, and Claudin-3 by western blotting. Following $S$. aureus infection, the mammary gland markedly reduced the expression of ZO-1, Occludin, and Claudin-3 when compared to the mammary gland without $S$. aureus stimulation (Fig. 6A-C). However, B. subtilis $\mathrm{H} 28$ treatment increased the levels of ZO-1, Occludin, and Claudin-3 compared to $S$. aureus-infected mice (Fig. $6 \mathrm{~A}-\mathrm{C}$ ). Furthermore, we confirmed Claudin-3 level of immunochemistry and showed that $B$. subtilis $H 28$ increased the Claudin-3 expression (Fig. 6D). To determine whether $B$. subtilis $\mathrm{H} 28$ inhibits the QS system 
and virulence, we measured the transcriptional level of AgrA, RNAIll, SarA through RTQ-PCR. We found that $B$. subtilis $\mathrm{H} 28$ could down-regulate the expression AgrA, RNAlll, and SarA as compared with that of the control group (Fig. 7A-C). Together, these results suggest that $B$. subtilis $\mathrm{H} 28$ inhibits $S$. aureus colonization and alleviates $S$. aureus-induced barrier damage by improving tight junctions.

\section{B. subtilis $\mathrm{H} 28$ inhibited S. aureus-induced inflammatory response in mouse mammary epithelial cells}

To verify the anti-inflammatory effect of $B$. subtilis $H 28$, the mouse mammary epithelial cells were pretreated with $B$. subtilis $H 28$ then stimulated with $S$. aureus. The activation of the NF-KB signaling pathway is responsible for the release of pro-inflammatory cytokines, such as TNF- $\alpha$ and IL-1 $\beta$.

Chemokines are a class of specific small-molecule proteins that play critical roles in the recruitment and activation of leukocytes (27). CXCL3 controls the migration and adhesion of monocytes by interacting with a cell surface chemokine receptor called CXCR2, which affects the secretion of cytokines (28). We found that $S$. aureus increased TNF-a, IL-1 $\beta$, IL-6 and CXCL3 mRNA levels (Fig. 8A-D) but reversed by $B$. subtilis $H 28$ treatment in a dose-dependent manner (Fig. 8A-D). Moreover, we found that $B$. subtilis $H 28$ reduced the expression ica, RNAlll, and SarA compared to $S$. aureus treatment in a dose-dependent manner (Fig. 8E-F).

\section{B. subtilis $\mathrm{H} 28$ limites the activation of NF-KB and increases tight junction protein expression in MMECs}

In order to study the effect of $B$. subtilis $\mathrm{H} 28$ on the integrity of the mammary gland epithelial cell induced by $S$. aureus, we found that $S$. aureus reduced the expression of Claudin-3, ZO-1, and Occludin. However, treatment with $B$. subtilis H28 increased the levels of Claudin 3, ZO-1 and Occludin in a dose-dependent manner (Fig. 9A-C). This is compatible with the results of in vitro experiments. To test whether the antiinflammatory properties of $B$. subtilis $H 28$ resulted from the regulation of the activation of the NF-kB, a predominant signaling pathway in $S$. aureus induced mastitis and associated with barrier injury, we assessed the levels of phosphorylation ( $p$-) levels of $p 65$ and IKB by western blotting and showed that the levels of p-p65 and p-IкB were significantly increased in the $S$. aureus group, while $B$. subtilis $H 28$ treatment markedly inhibited the activation of the NF-KB signaling pathway in a dose-dependent manner (Fig. 9A and E-F). Collectively, these results suggest that $B$. subtilis $H 28$ alleviates $S$. aureus-induced mastitis by improving tight junction protein expression and limiting NF-KB pathway activation.

\section{Discussion}

Mastitis constitutes one of the aggressive diseases that affecting the development of dairy farming. $S$. aureus is the most frequent and important pathogen causing mastitis in dairy cows (29). Bacillus as one of the normal host-microbiota exists in the mammary gland of cows (30). But the functional Bacillus and their role in $S$. aureus-induced mastitis pathogenesis remain poorly defined. The aim of our study was to elucidate the distinctive contribution of Bacillus in S. aureus mastitis. In studies, we found that there is interference between the mammary symbiotic bacterium Bacillus and the pathogenic bacterium $S$. aureus. Bacillus can down-regulate the gene expression of the QS system of $S$. aureus to inhibit the biofilm formation of $S$. aureus and thus reduce the amount of colonization of $S$. aureus. In treatment with 
Bacillus in mice mastitis, the result showed that preparations of the Bacillus were as effective as commonly used antibiotics relieving $S$. aureus-induced mastitis for the treatment of intramammary infections and did not show adverse effects on mammary tissue.

Probiotic nutrition is frequently claimed to be improve health. Probiotic bacteria obtained with food are thought to decrease colonization by pathogens, and thus reduce susceptibility to infection (31-33). Some probiotic strains produce bacteriocin proteins, which can kill phylogenetically related pathogenic bacteria (31). It is particularly noteworthy human data indicate that probiotic Bacillus can comprehensively eradicate intestinal as well as nasal $S$. aureus colonization (18). Epidemiological studies have established that there is interference between the mammary symbiotic bacterium Bacillus and the pathogenic bacterium $S$. aureus. Bacillus can reduce the colonization of mammary glands by $S$. aureus in dairy cows. it was shown that the presence of Bacillus in the gland mammary could be a potential determining factor for the absence of $S$. aureus in cows.

Several studies have reported that in addition to the potential probiotic properties of Bacillus strains, the Bacillus exhibited strong anti-cholesterol, anti-biofilm, and antioxidant properties, making the strain with additional functional abilities (34). B. subtilis exerts an antimicrobial effect against a broad spectrum of pathogens through direct bactericidal activity or indirect enhancement of immune response, such as interrupting quorum-sensing regulatory system by production of fengycins (18), inhibiting $S$. aureus adhesion and biofilm formation by production of surfactant (35), and the enhancing anti-microbial function of macrophage (36). We study has confirmed a potent inhibitory capacity of $B$. subtilis $\mathrm{H} 28$ against both planktonic and biofilm $S$. aureus in vitro, which may prominently suppress the expression of genes associated with $S$. aureus adhesion, biofilm formation.

QS plays an essential role in biofilm formation, in the production of virulence factors and antimicrobial resistance (37). There is evidence that quorum sensing in $S$. aureus is important for the construction and dissolution of biofilm communities (38). The QS system controls $S$. aureus biofilm formation and release of virulence factors $(21,39)$. Researchers believe that the accessory gene regulator (agr) system regulates the QS in S. aureus (40). In fact, agr plays a pivotal role in regulating virulence factor expression (41), making it a potential therapeutic target (42). Biofilm formation is believed to require the adhesion of cells to a solid substrate, which creates multiple layers of cells. Intercellular adhesion requires PIA, which can be synthesized by-products of the intercellular adhesion (ica) $\operatorname{locus}(23,24)$. The RNAlll activating peptide is thought to be a type of auto-inducing peptide $(25,26)$ that can phosphorylate its target molecule to activate the agr system, which increases the production of auto inducing peptides and AgrC to enhance the adhesion of the bacteria $[36,37]$. Recent findings indicate that RNAIII is a regulatory mRNA molecule that not only regulates biofilm formation but also induces toxin production, such as enterotoxin, plasmacoagulase, hemolysin, and thermostable nuclease $(26,43)$. In addition, it is a fellow of the staphylococcal accessory regulator A (SarA) family of transcriptional regulators (44). Recent evidence indicates that SarA, a central regulatory element that controls the production of $S$. aureus virulence factors, is essential for the synthesis of polysaccharide intercellular adhesin (PIA) (45). We have shown that $B$. subtilis $\mathrm{H} 28$ could inhibit biofilm formation by $S$. aureus phenotypically. To determine whether $B$. subtilis $H 28$ inhibits 
the QS system and virulence, we analyzed the effects of $B$. subtilis $H 28$ on the expression of $S$. aureus genes involved in quorum sensing (AgrA and RNAIII) and biofilm formation (Ica and SarA). We found that B. subtilis $\mathrm{H} 28$ could down-regulate the expression of genes agrA, RNAll, ica, and sarA associated with the QS system. B. subtilis $\mathrm{H} 28$ effectively inhibited the QS system of $S$. aureus in a dose-dependent manner, resulting in inhibition of biofilm formation. B. subtilis $\mathrm{H} 28$ might be considered a QS inhibitor because of its ability to block the cell-to-cell signal transduction that is regulated by the QS system, and thus inhibiting expression of QS-related genes. The specific mechanism by which $B$. subtilis $\mathrm{H} 28$ inhibits the QS system requires further study and discussion, but the net outcome of QS inhibition is inhibition of biofilm formation. Therefore, we believe $B$. subtilis $\mathrm{H} 28$ is potential novel treatment against $S$. aureus biofilm-related infections.

Therefore, we further investigated in the next study whether $B$. subtilis $\mathrm{H} 28$ can have a protective effect against mastitis caused by $S$. aureus. Recently, the intramammary infusion of lactic acid bacteria has emerged as a potential new alternative to antibiotics for preventing and treating bovine mastitis (46). We took the same mammary gland infusion and an important finding in this study is that the intramammary infusion of $B$. subtilis $H 28$ can significantly reduce $S$. aureus colonization to alleviate $S$. aureus-induced mastitis.

Our study suggests valuable translational applications regarding alternative strategies to combat antibiotic-resistant $S$. aureus. Bacillus-containing probiotics could be used in order to simple and safe $S$. aureus decolonization strategies. In that regard, it is particularly noteworthy that our data indicate that probiotic Bacillus can eradicate mammary $S$. aureus colonization. Such a probiotic approach would have numerous advantages over the present standard topical strategy involving antibiotics. Bacillus provides a reasonable reference for the treatment of inflammatory diseases. Therefore, our study provided support for the probiotic effect of Bacillus and Bacillus may have the potential as a promising candidate for the treatment of mastitis.

At the same time, the study has a few limitations. The specific mechanisms responsible for the inhibition of the QS system by $B$. subtilis $\mathrm{H} 28$ need to be further investigated and discussed. In addition to this, it was observed Bacillus can reduce the colonization of mammary glands by $S$. aureus in cows and was confirmed in mice. However, all the experiments evaluating the effects of this defect were carried out in mice, which can be seen as a potential limitation. Further interventional studies in cows should be made to evaluate the proposed therapeutic strategy. Our future research will focus on the cows in vivo to identify the precise mechanism by which $B$. subtilis $H 28$ inhibits $\mathrm{S}$. aureus biofilm formation.

\section{Conclusions}

Collectively, our results indicate that commensal Bacillus inhibits $S$. aureus colonization and alleviates $S$. aureus-induced mastitis by influencing biofilm formation, which suggests a potential strategy for the decolonization of $\mathrm{S}$. aureus and acts as a basis for the prevention and treatment of $\mathrm{S}$. aureus-related disease. 


\section{Declarations}

\section{Author contributions}

Min Qiu performed the article writing and result evaluation. Caijin Zhao performed histologic analysis and article revision. Xiaoyu Hu performed the final revision of the article and provided expert opinion. Lianjun Feng, Siyuan Gao contributed to animal experiment. Naisheng Zhang and Yunhe Fu contributed to the study design.

\section{Conflicts of interest}

The authors declare that they have no conflicts of interest.

\section{Funding}

The present study was supported by the National Natural Science Foundation of China (31972749 and 31772812) and the China Postdoctoral Science Foundation (2020TQ0120 and 2020M681045). The funders had no role in study design, data collection and analysis, decision to publish, or preparation of the manuscript.

\section{Acknowledgements}

Authors thank all constructive suggestions from Zhang's Lab.

\section{Compliance with ethical standards}

\section{Ethical statement}

The permit number (202103058) was assigned by the Institutional Animal Care and Use Committee (IACUC) of Jilin University for animal experiments approvals. The full proposal was reviewed by the IACUC ethics committee, which approved the animal care and use permit license. All experiments comply with the manual of the care and use of laboratory animals published by the US National Institutes of Health.

\section{Data Availability}

All data analyzed during this study are included within this article. Any other data are available from the corresponding author upon reasonable request.

\section{References}

1. Ruegg PL. A 100-Year Review: Mastitis detection, management, and prevention. J Dairy Sci. 2017;100(12):10381-97. 
2. Cai J, Li J, Zhou YQ, Wang JQ, Li JJ, Cui LY, et al. Staphylococcus aureus facilitates its survival in bovine macrophages by blocking autophagic flux. J Cell Mol Med. 2020;24(6):3460-8.

3. Gogoi-Tiwari J, Williams V, Waryah CB, Mathavan S, Tiwari HK, Costantino P, et al. Intramammary Immunization of Pregnant Mice with Staphylococcal Protein A Reduces the Post-Challenge Mammary Gland Bacterial Load but Not Pathology. Plos One. 2016;11(2).

4. Spaulding AR, Lin YC, Merriman JA, Brosnahan AJ, Peterson ML, Schlievert PM. Immunity to Staphylococcus aureus secreted proteins protects rabbits from serious illnesses. Vaccine. 2012;30(34):5099-109.

5. Di Domenico EG, Cavallo I, Capitanio B, Ascenzioni F, Pimpinelli F, Morrone A, et al. Staphylococcus aureus and the Cutaneous Microbiota Biofilms in the Pathogenesis of Atopic Dermatitis. Microorganisms. 2019;7(9).

6. Dotto C, Serrat AL, Ledesma M, Vay C, Ehling-Schulz M, Sordelli DO, et al. Salicylic acid stabilizes Staphylococcus aureus biofilm by impairing the agr quorum-sensing system. Sci Rep-Uk. 2021;11(1).

7. Bhardwaj RG, Ellepolla A, Drobiova H, Karched M. Biofilm growth and IL-8 \& TNF-alpha-inducing properties of Candida albicans in the presence of oral gram-positive and gram-negative bacteria. Bmc Microbiol. 2020;20(1):156.

8. Howden BP, McEvoy CR, Allen DL, Chua K, Gao W, Harrison PF, et al. Evolution of multidrug resistance during Staphylococcus aureus infection involves mutation of the essential two component regulator WalKR. PLoS Pathog. 2011;7(11):e1002359.

9. Silva V, Capelo JL, Igrejas G, Poeta P. Molecular Epidemiology of Staphylococcus aureus Lineages in Wild Animals in Europe: A Review. Antibiotics-Basel. 2020;9(3).

10. Gao A, Mei GY, Liu S, Wang P, Tang Q, Liu YP, et al. High-resolution structures of AidH complexes provide insights into a novel catalytic mechanism for $\mathrm{N}$-acyl homoserine lactonase. Acta Crystallogr D. 2013;69:82-91.

11. Dourado MN, Bogas AC, Pomini AM, Andreote FD, Quecine MC, Marsaioli AJ, et al. Methylobacteriumplant interaction genes regulated by plant exudate and quorum sensing molecules. Braz J Microbiol. 2013;44(4):1331-9.

12. Zeng Z, Qian L, Cao L, Tan H, Huang Y, Xue X, et al. Virtual screening for novel quorum sensing inhibitors to eradicate biofilm formation of Pseudomonas aeruginosa. Appl Microbiol Biot. 2008;79(1):119-26.

13. Chen JA, Zhou HY, Huang JB, Zhang R, Rao XC. Virulence alterations in staphylococcus aureus upon treatment with the sub-inhibitory concentrations of antibiotics. J Adv Res. 2021;31:165-75.

14. Peng XD, Ekanayaka SA, McClellan SA, Barrett RP, Vistisen K, Hazlett LD. Characterization of Three Ocular Clinical Isolates of P. aeruginosa: Viability, Biofilm Formation, Adherence, Infectivity, and Effects of Glycyrrhizin. Pathogens. 2017;6(4).

15. Oikonomou G, Bicalho ML, Meira E, Rossi RE, Foditsch C, Machado VS, et al. Microbiota of cow's milk; distinguishing healthy, sub-clinically and clinically diseased quarters. Plos One. 2014;9(1):e85904. 
16. Lv PH, Song YY, Liu C, Yu LP, Shang YL, Tang H, et al. Application of Bacillus subtilis as a live vaccine vector: A review. J Vet Med Sci. 2020;82(11):1693-9.

17. Barboza-Corona JE, de la Fuente-Salcido N, Alva-Murillo N, Ochoa-Zarzosa A, Lopez-Meza JE. Activity of bacteriocins synthesized by Bacillus thuringiensis against Staphylococcus aureus isolates associated to bovine mastitis. Vet Microbiol. 2009;138(1-2):179-83.

18. Piewngam P, Zheng Y, Nguyen TH, Dickey SW, Joo HS, Villaruz AE, et al. Pathogen elimination by probiotic Bacillus via signalling interference. Nature. 2018;562(7728):532-7.

19. Elshaghabee FMF, Rokana N, Gulhane RD, Sharma C, Panwar H. Bacillus As Potential Probiotics: Status, Concerns, and Future Perspectives. Front Microbiol. 2017;8.

20. Kiran MD, Adikesavan NV, Cirioni O, Giacometti A, Silvestri C, Scalise G, et al. Discovery of a quorumsensing inhibitor of drug-resistant staphylococcal infections by structure-based virtual screening. Mol Pharmacol. 2008;73(5):1578-86.

21. Parsek MR, Greenberg EP. Sociomicrobiology: the connections between quorum sensing and biofilms. Trends Microbiol. 2005;13(1):27-33.

22. Kleerebezem M, Quadri LE, Kuipers OP, de Vos WM. Quorum sensing by peptide pheromones and two-component signal-transduction systems in Gram-positive bacteria. Mol Microbiol. 1997;24(5):895-904.

23. Quave CL, Estevez-Carmona M, Compadre CM, Hobby G, Hendrickson H, Beenken KE, et al. Ellagic acid derivatives from Rubus ulmifolius inhibit Staphylococcus aureus biofilm formation and improve response to antibiotics. Plos One. 2012;7(1):e28737.

24. Coelho LR, Souza RR, Ferreira FA, Guimaraes MA, Ferreira-Carvalho BT, Figueiredo AMS. agr RNAIII divergently regulates glucose-induced biofilm formation in clinical isolates of Staphylococcus aureus. Microbiology (Reading). 2008;154(Pt 11):3480-90.

25. Reading NC, Sperandio V. Quorum sensing: the many languages of bacteria. FEMS Microbiol Lett. 2006;254(1):1-11.

26. Shiner EK, Rumbaugh KP, Williams SC. Inter-kingdom signaling: deciphering the language of acyl homoserine lactones. FEMS Microbiol Rev. 2005;29(5):935-47.

27. Chen Y, Chen Q, Xie F, Peng H, Wu Y, Zhong S, et al. Traditional Chinese Medicine Extract from Huaier Increases the Expression of Duffy Antigen Receptor for Chemokines and Reduces the Expression of Its Ligands. Anal Cell Pathol (Amst). 2018;2018:6756092.

28. Vogel CF, Chang WL, Kado S, McCulloh K, Vogel H, Wu D, et al. Transgenic Overexpression of Aryl Hydrocarbon Receptor Repressor (AhRR) and AhR-Mediated Induction of CYP1A1, Cytokines, and Acute Toxicity. Environ Health Perspect. 2016;124(7):1071-83.

29. Cai L, Tong J, Zhang Z, Zhang Y, Jiang L, Hou X, et al. Staphylococcus aureus-induced proteomic changes in the mammary tissue of rats: A TMT-based study. Plos One. 2020;15(5):e0231168.

30. Yu J, Ren Y, Xi X, Huang W, Zhang H. A Novel Lactobacilli-Based Teat Disinfectant for Improving Bacterial Communities in the Milks of Cow Teats with Subclinical Mastitis. Front Microbiol. 2017;8:1782. 
31. Kamada N, Chen GY, Inohara N, Nunez G. Control of pathogens and pathobionts by the gut microbiota. Nat Immunol. 2013;14(7):685-90.

32. Bermudez-Brito M, Plaza-Diaz J, Munoz-Quezada S, Gomez-Llorente C, Gil A. Probiotic mechanisms of action. Ann Nutr Metab. 2012;61(2):160-74.

33. Gourbeyre P, Denery S, Bodinier M. Probiotics, prebiotics, and synbiotics: impact on the gut immune system and allergic reactions. J Leukoc Biol. 2011;89(5):685-95.

34. Shivangi S, Devi PB, Ragul K, Shetty PH. Probiotic Potential of Bacillus Strains Isolated from an Acidic Fermented Food Idli. Probiotics Antimicrob Proteins. 2020;12(4):1502-13.

35. Liu J, Li W, Zhu X, Zhao H, Lu Y, Zhang C, et al. Surfactin effectively inhibits Staphylococcus aureus adhesion and biofilm formation on surfaces. Appl Microbiol Biotechnol. 2019;103(11):4565-74.

36. Lefevre M, Racedo SM, Ripert G, Housez B, Cazaubiel M, Maudet C, et al. Probiotic strain Bacillus subtilis CU1 stimulates immune system of elderly during common infectious disease period: a randomized, double-blind placebo-controlled study. Immun Ageing. 2015;12:24.

37. Luo LM, Wu LJ, Xiao YL, Zhao D, Chen ZX, Kang M, et al. Enhancing pili assembly and biofilm formation in Acinetobacter baumannii ATCC19606 using non-native acyl-homoserine lactones. Bmc Microbiol. 2015;15:62.

38. Qin N, Tan X, Jiao Y, Liu L, Zhao W, Yang S, et al. RNA-Seq-based transcriptome analysis of methicillin-resistant Staphylococcus aureus biofilm inhibition by ursolic acid and resveratrol. Sci Rep. 2014;4:5467.

39. Kiran MD, Adikesavan NV, Cirioni O, Giacometti A, Silvestri C, Scalise G, et al. Discovery of a quorumsensing inhibitor of drug-resistant staphylococcal infections by structure-based virtual screening. Mol Pharmacol. 2008;73(5):1578-86.

40. Leung V, Ajdic D, Koyanagi S, Levesque CM. The Formation of Streptococcus mutans Persisters Induced by the Quorum-Sensing Peptide Pheromone Is Affected by the LexA Regulator. J Bacteriol. 2015;197(6):1083-94.

41. Recsei P, Kreiswirth B, O'Reilly M, Schlievert P, Gruss A, Novick RP. Regulation of exoprotein gene expression in Staphylococcus aureus by agar. Mol Gen Genet. 1986;202(1):58-61.

42. Vuong C, Durr M, Carmody AB, Peschel A, Klebanoff SJ, Otto M. Regulated expression of pathogenassociated molecular pattern molecules in Staphylococcus epidermidis: quorum-sensing determines pro-inflammatory capacity and production of phenol-soluble modulins. Cell Microbiol. 2004;6(8):7539.

43. Oikonomou G, Bicalho ML, Meira E, Rossi RE, Foditsch C, Machado VS, et al. Microbiota of Cow's Milk; Distinguishing Healthy, Sub-Clinically and Clinically Diseased Quarters. Plos One. 2014;9(1).

44. Tamber S, Cheung AL. SarZ promotes the expression of virulence factors and represses biofilm formation by modulating SarA and agr in Staphylococcus aureus. Infect Immun. 2009;77(1):419-28.

45. Beenken KE, Dunman PM, McAleese F, Macapagal D, Murphy E, Projan SJ, et al. Global gene expression in Staphylococcus aureus biofilms. J Bacteriol. 2004;186(14):4665-84. 
46. Fukuyama K, Islam MA, Takagi M, Ikeda-Ohtsubo W, Kurata S, Aso H, et al. Evaluation of the Immunomodulatory Ability of Lactic Acid Bacteria Isolated from Feedlot Cattle Against Mastitis Using a Bovine Mammary Epithelial Cells In Vitro Assay (vol 9, 410, 2020). Pathogens. 2020;9(7).

\section{Figures}

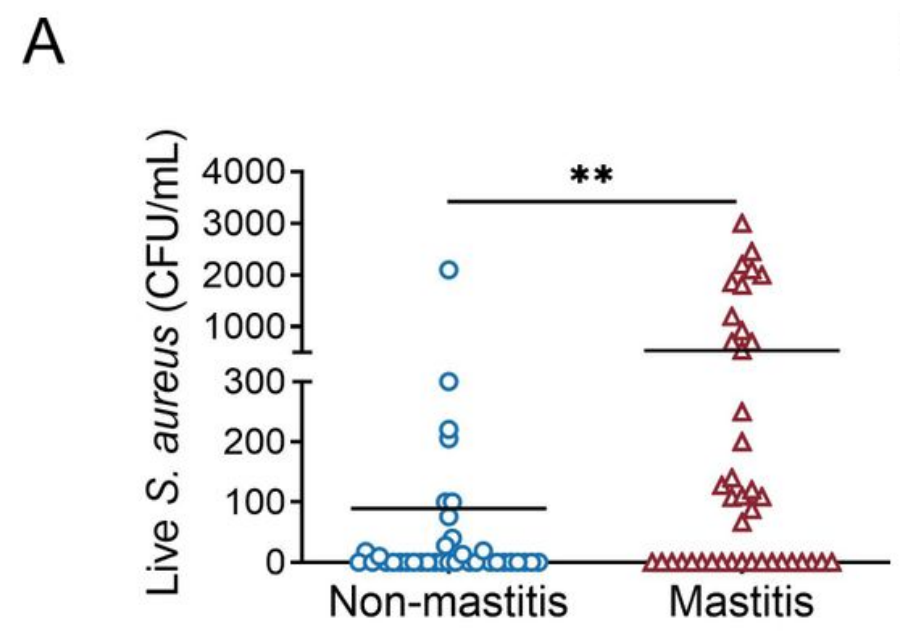

B
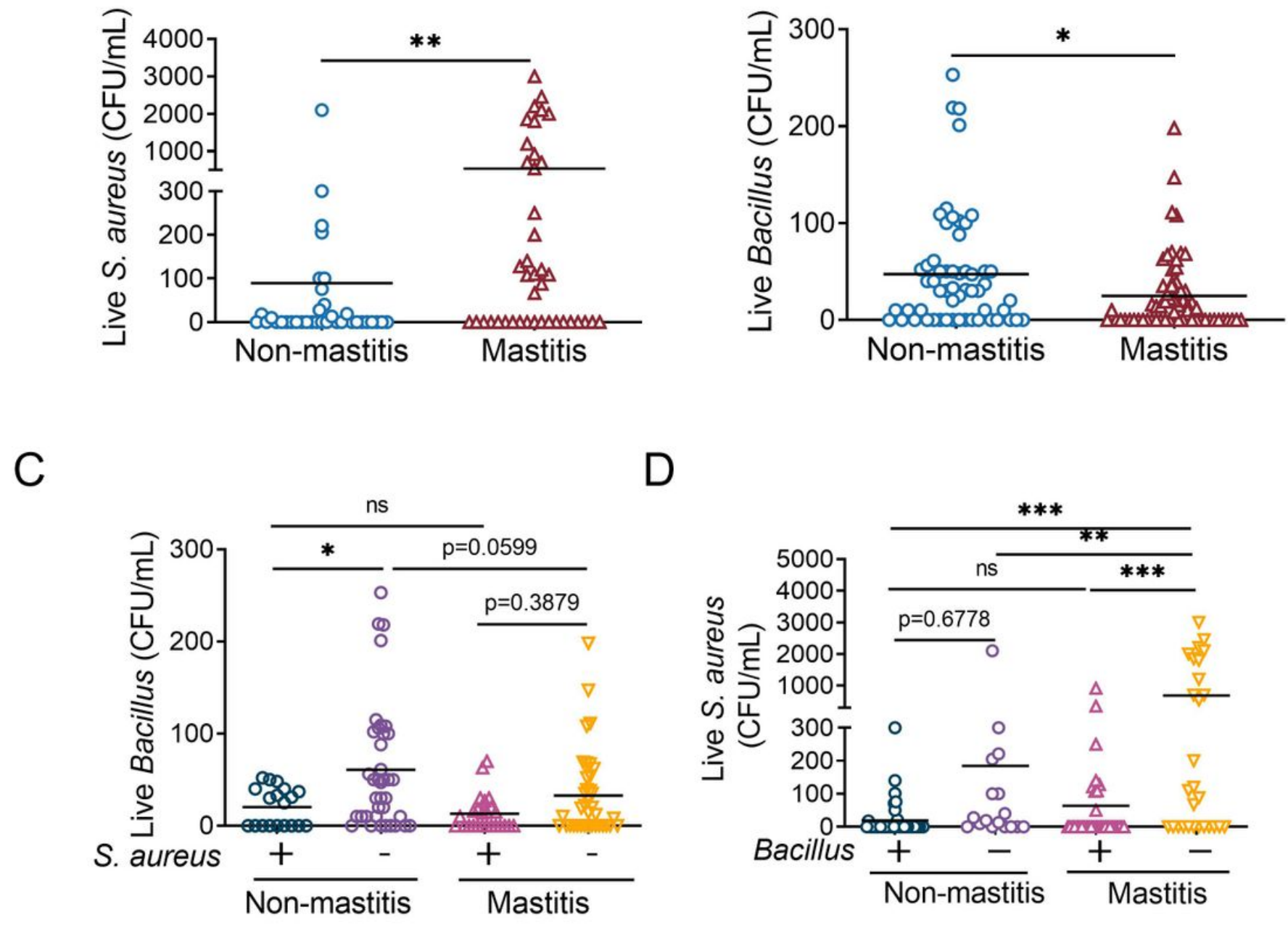

Figure 1

Mastitis cows have increased S. aureus and reduced Bacillus colonization in the milk. (A) Live S. aureus CFUs in non-mastitis cows and mastitis cows. (B) Live Bacillus CFUs in non-mastitis cows and mastitis cows. (C) Effect of the presence or absence of $S$. aureus on the live Bacillus CFUs in non-mastitis cows and mastitis cows. (D) Effect of the presence or absence of Bacillus on the live S. aureus CFUs in non- 
mastitis cows and mastitis cows. One-way analysis of variance was used for statistical analysis. ${ }^{*} \mathrm{p}$ 0.05 and ${ }^{*} p<0.01$ and $* * * p \rrbracket 0.001$ indicate significant differences from each group. ns, no significance.

A

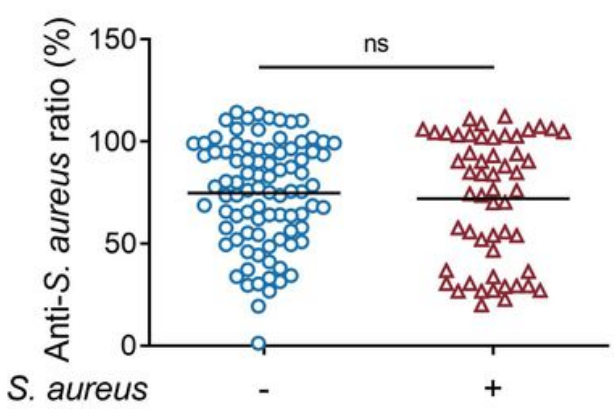

B

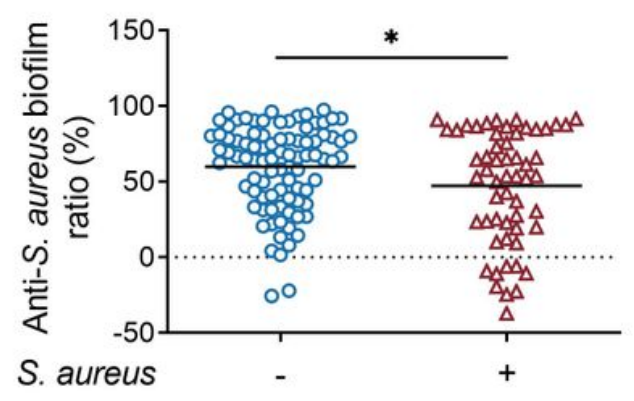

C

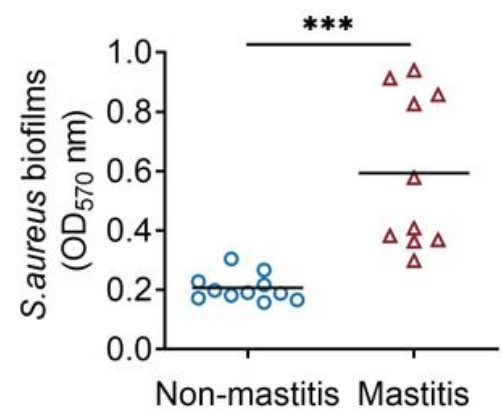

\section{Figure 2}

S. aureus from mastitis have higher biofilm formation capacity but inhibited by commensal Bacillus. (A) Effect of Bacillus on the growth of S. aureus. (B) Effect of Bacillus on the biofilm of S. aureus. (C) S. aureus biofilm forming ability in non-mastitis cows and mastitis cows. One-way analysis of variance was used for statistical analysis. The values presented are the mean \pm SEM $(n=4)$. ${ }^{*} p<0.05$ and ${ }^{*} p<0.01$ and ${ }^{* * \star} \mathrm{p} \otimes 0.001$ indicate significant differences from each group. ns, no significance. 
A

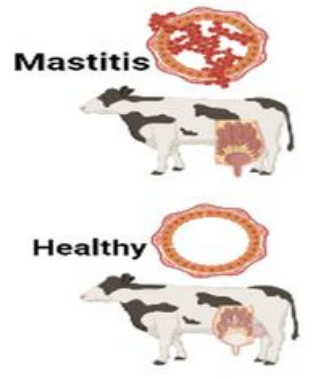

Anti-S.aureus Bacillus

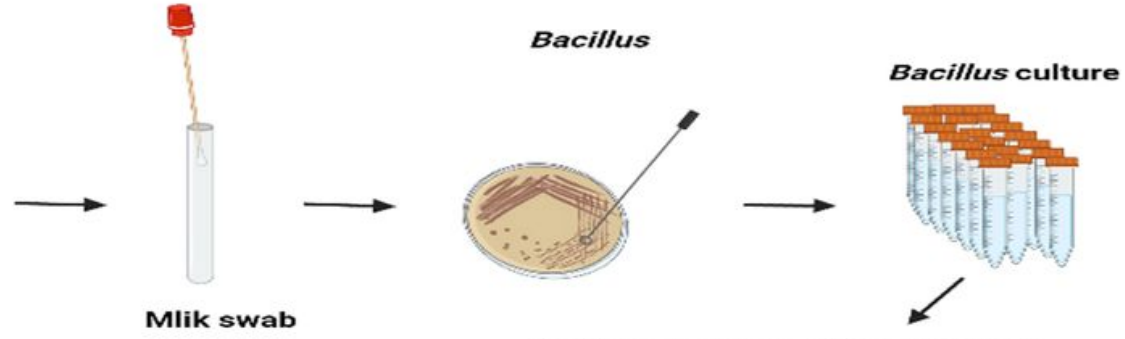

Bacteria-free conditionemd media Culture with S.aureus

B

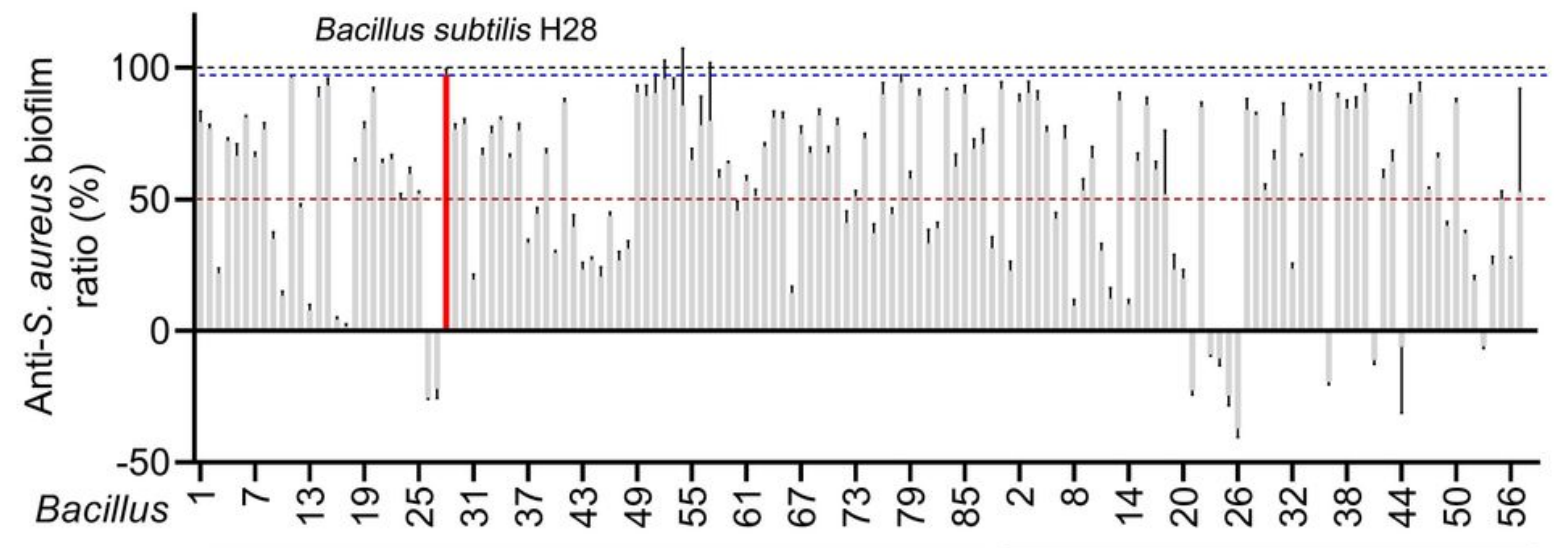

S. aureus negative

C

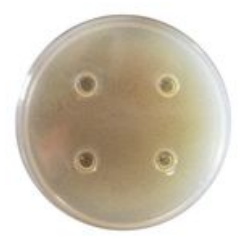

D

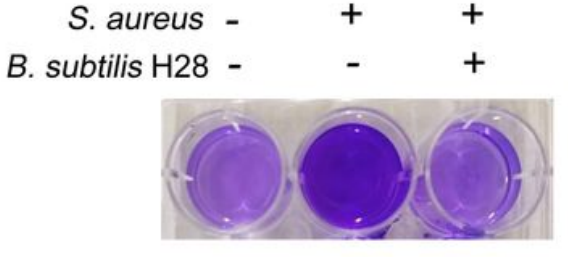

S. aureus positive

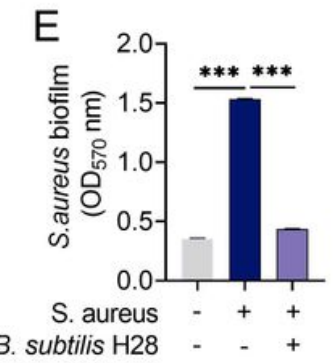

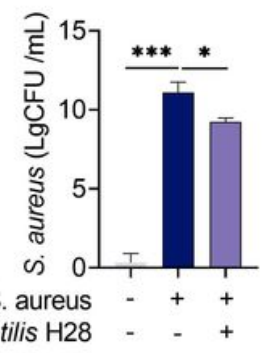

\section{Figure 3}

B. subtilis $\mathrm{H} 28$ isolated from healthy cow inhibited S. aureus biofilm. (A) Schematic of a high-throughput anti-biofilm screening of Bacillus against S. aureus. (B)Percentage of anti-biofilm effect of Bacillus without $(₫ 50 \%)$ or with anti-biofilm activity against $\mathrm{S}$. aureus $(\varangle 50 \%)$. The first 87 strains of Bacillus were isolated from healthy cows. The last 58 Bacillus strains were isolated from cows with S. aureus-mastitis. Red is the strain with the best biofilm effect against S. aureus, i.e., B. subtilis H28. (C) Antibacterial effect of $B$. subtilis $\mathrm{H} 28$ detected by inhibition circle. a and b add TBS, $c$ and d add B. subtilis H28 culture filtrate. (D) Representative images of crystal violet staining for S. aureus biofilm. Quantitative analysis of biofilm formation by crystal violet-staining was dissolved and measured at $570 \mathrm{~nm}$ in a microplate reader. (E) Intra-biofilm S. aureus count. One-way analysis of variance was used for statistical analysis. 
The values presented are the mean \pm SEM $(n=4) .{ }^{*} p<0.05$ and ${ }^{*} p<0.01$ and ${ }^{\star * *} p \otimes 0.001$ indicate significant differences from each group. ns, no significance.

A

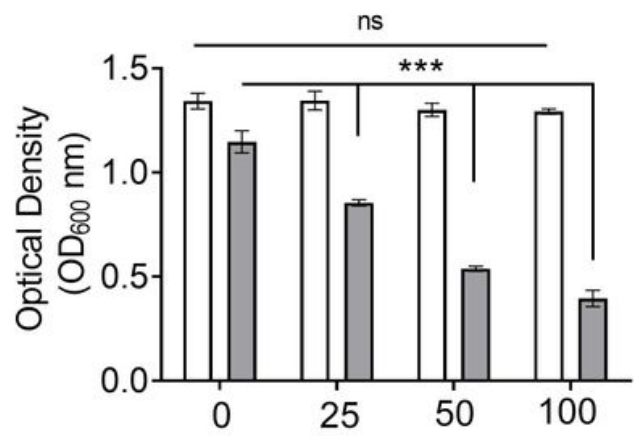

Concentration of $B$. subtilis $\mathrm{H} 28$ culture filtrates (\%)

$\square \begin{aligned} & \text { Inhibition of } \\ & \text { S.aureus growth }\end{aligned}$ Anti-S.aureus Biofilm
B

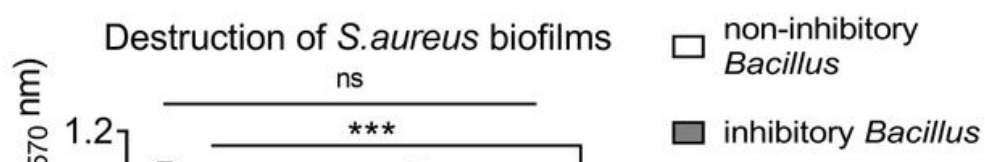

C

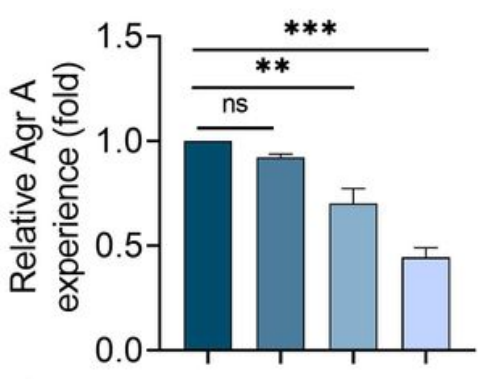

S. aureus ++++ B. subtilis $\mathrm{H} 28(\%) \quad-\quad 25 \quad 50100$
D

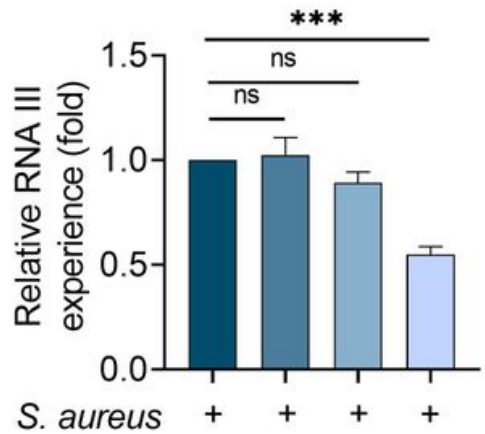

B. subtilis $\mathrm{H} 28(\%) \quad-2550100$
$\mathrm{E}$

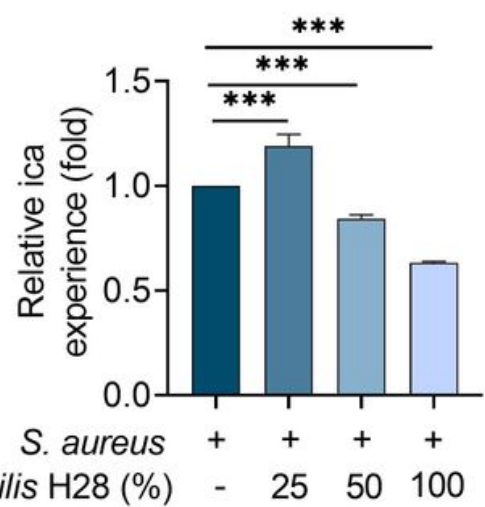

\section{Figure 4}

B. subtilis $\mathrm{H} 28$ limits S. aureus biofilm formation by inhibiting QS system (A) Effect of $25 \%, 50 \%, 100 \%$ B. subtilis $\mathrm{H} 28$ culture filtrates on the growth of S. -aureus and on S. aureus biofilm. (B) Destructive effect of $25 \%, 50 \%$ and $100 \%$ B. subtilis H28 culture filtrate on the formed biofilm of S. aureus. Meanwhile, noninhibiting Bacillus, which has no biofilm inhibitory effect on S. aureus, was used as a comparison. (C) Relative expression of the AgrA was identified using qPCR. (D) Relative expression of the RNAヌwere identified using qPCR. (E) Relative expression of the ica was identified using qPCR. One-way analysis of variance was used for statistical analysis. The values presented are the mean \pm SEM $(n=3) .{ }^{*} p<0.05$ and ${ }^{*} \mathrm{p}<0.01$ and ${ }^{* \star *} \mathrm{p} \otimes 0.001$ indicate significant differences from each group. ns, no significance. 
A

Control

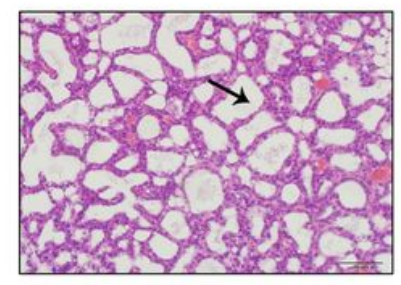

B. subtilis $\mathrm{H} 28$

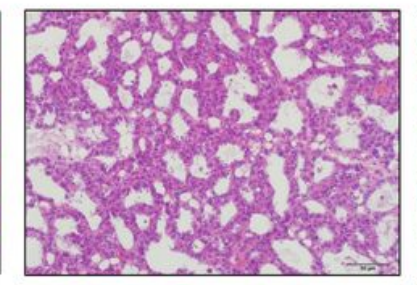

S. aureus

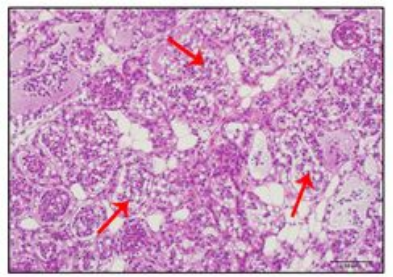

B. subtilis $\mathrm{H} 28+\mathrm{S}$. aureus

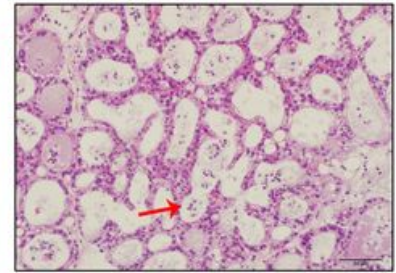

B

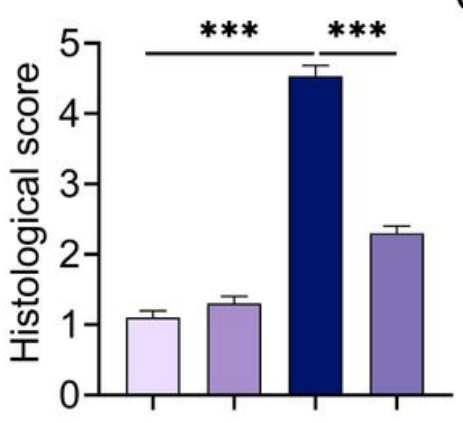

S. aureus - - + +
C

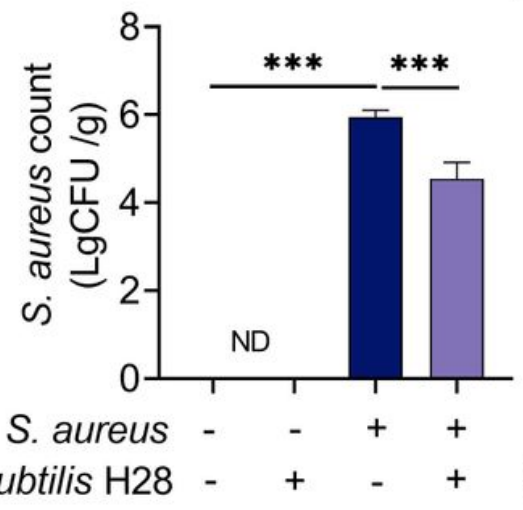

D

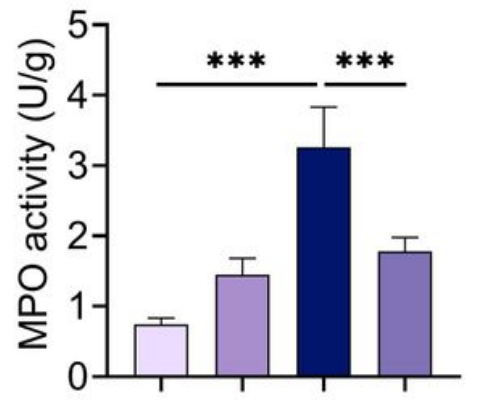

S. aureus - -++
E

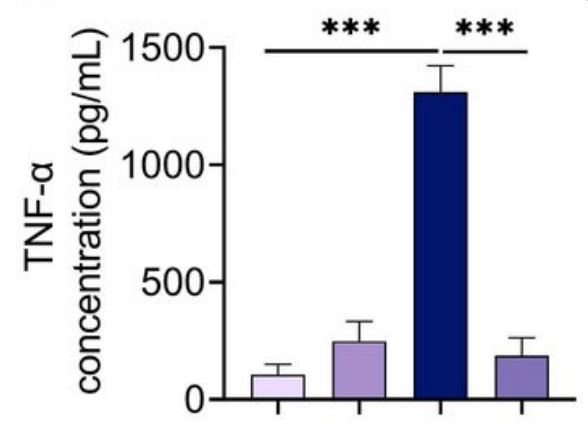

S. aureus - - ++

$\mathrm{F}$

B. subtilis $\mathrm{H} 28-+\quad+$

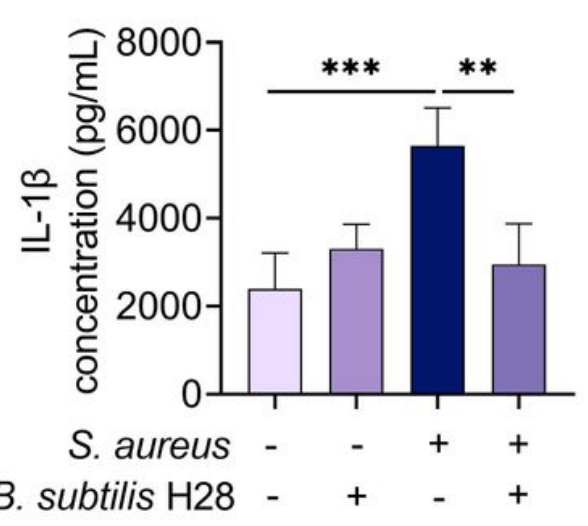

Figure 5

B. subtilis $\mathrm{H} 28$ alleviates $\mathrm{S}$. aureus induced mastitis in mice. B. subtilis $\mathrm{H} 28(1 \times 108 \mathrm{CFU})$ was administered to the mammary glands of mice $2 \mathrm{~h}$ before infection with $\mathrm{S}$. aureus $(1 \times 108 \mathrm{CFU})$. Twentyfour hours later, mammary gland tissues were collected and used for testing. (A) Pathological changes were detected with H\&E (200x). The black arrow indicates normal alveolar cells. The red arrow indicates the inflammatory cells infiltration. (B) Histopathologic scoring. (C) Mammary tissue S. aureus count. (D) MPO activity. (E)TNF- $\alpha$ and (F) IL-1 $\beta$ in the mammary gland tissues. The values presented are the mean \pm SEM $(n=5-6)$. One-way analysis of variance was used for statistical analysis. ${ }^{*} p<0.05$ and ${ }^{*} p<0.01$ and $\star \star \star \mathrm{p} \llbracket 0.001$ indicate significant differences from each group. ns, no significance. 
A

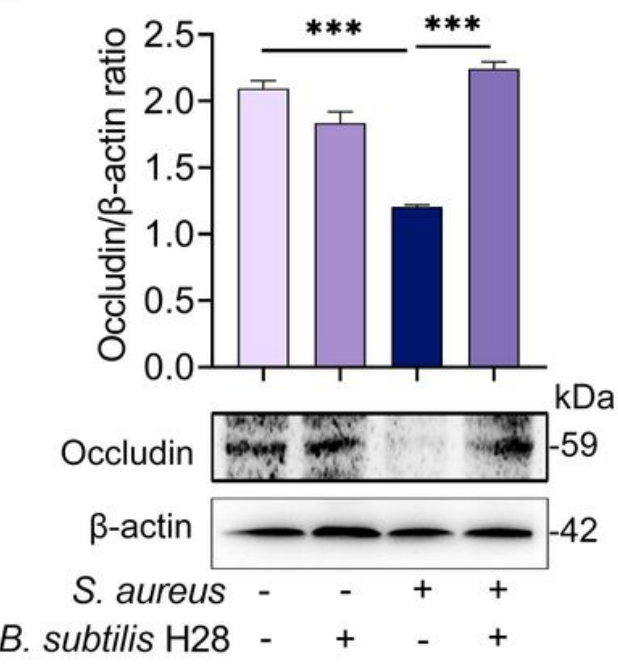

B
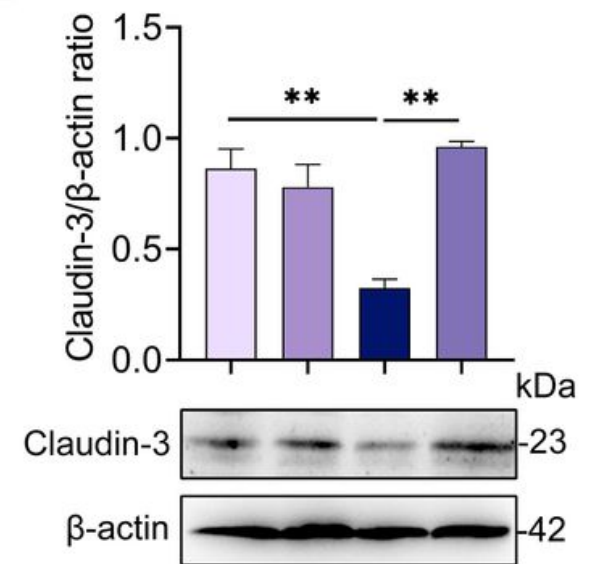

S. aureus - -++
C

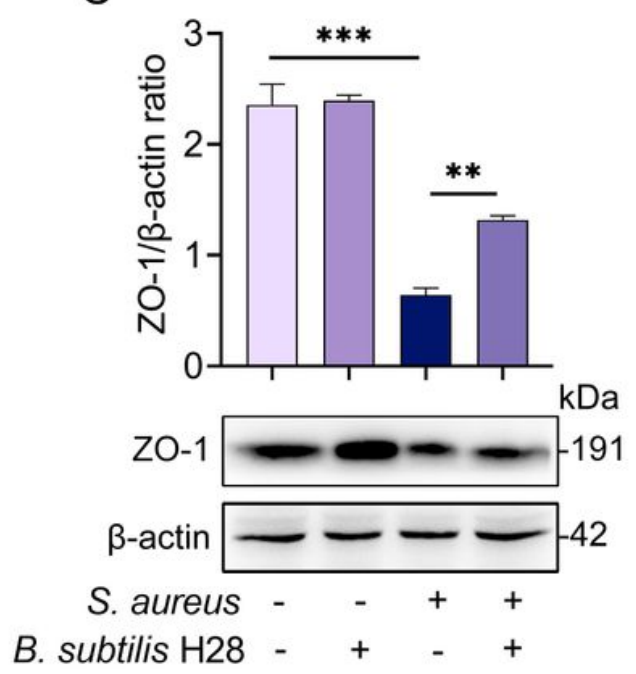

B. subtilis $\mathrm{H} 28-+\quad+$

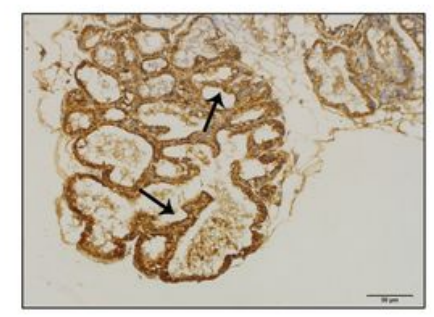

Control

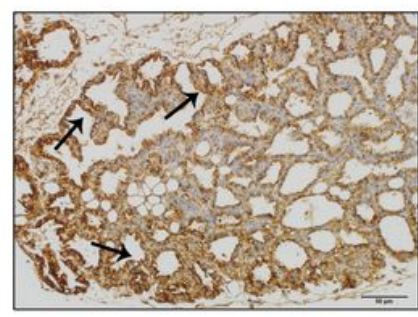

B. subtilis $\mathrm{H} 28$

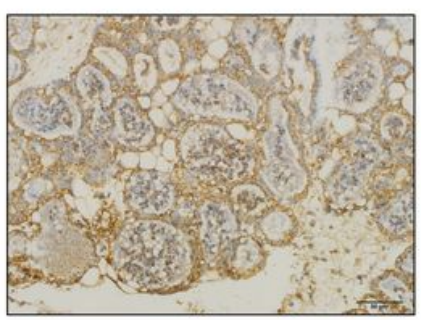

S. aureus

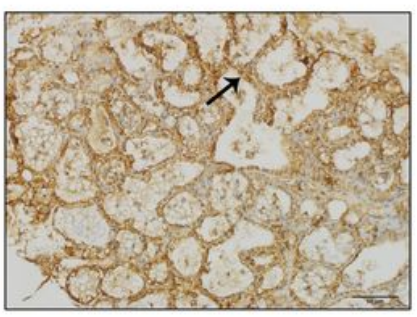

B. subtilis $\mathrm{H} 28+\mathrm{S}$. aureus

Figure 6

Effects of B. subtilis $\mathrm{H} 28$ on the distribution of tight junction proteins Expression of tight junction proteins by western blotting, including Occludin, Claudin-3, and ZO-1, was tested $24 \mathrm{~h}$ after infection in in mice mammary gland. The values presented are the mean \pm SEM $(n=3-4)$. One-way analysis of variance (A-C) was used for statistical analysis. ${ }^{*} p<0.05$ and ${ }^{*} p<0.01$ and $* * * p \llbracket 0.001$ indicate significant differences from each group. ns, no significance. (D) Representative images of mammary gland immunohistochemistry (IHC) sections stained with Claudin-3 antibody (scale bar, $50 \mu \mathrm{m}$ ). The black arrow indicates the positive staining. 
A

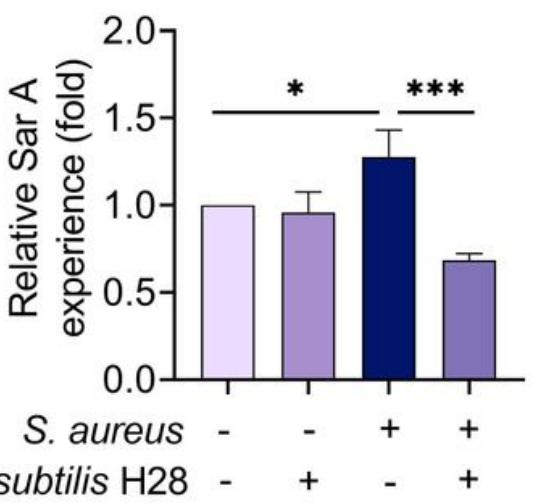

B

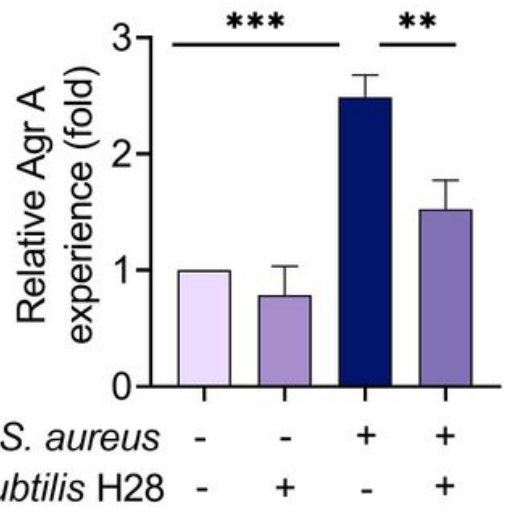

C

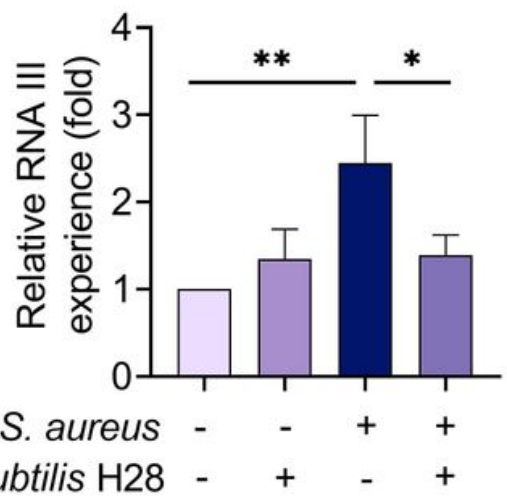

\section{Figure 7}

Effect of B. subtilis H28 expression of QS related genes in mice mammary gland (A) Relative expression of the SarA was identified using qPCR. (B) Relative expression of the RNA $\triangle$ was identified using qPCR. (C) Relative expression of the Agr A was identified using qPCR. The values presented are the mean \pm $\operatorname{SEM}(n=3)$. One-way analysis of variance was used for statistical analysis. ${ }^{*} p<0.05$ and ${ }^{*} p<0.01$ and $\star \star \star p \rrbracket 0.001$ indicate significant differences from each group. ns, no significance. 
A

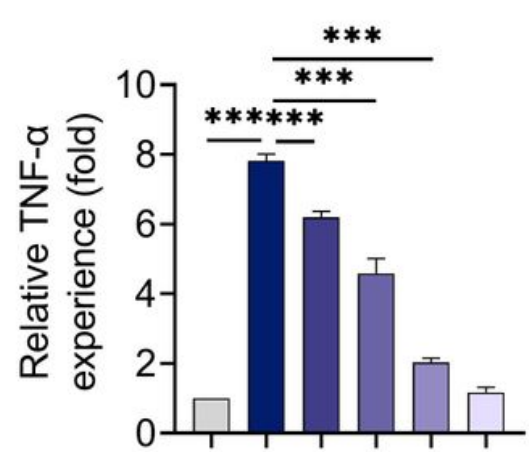

S. aureus - + + + -

B. subtilis $\mathrm{H} 28$ - - $10^{7} 10^{8} 10^{9} 10^{9}$

D

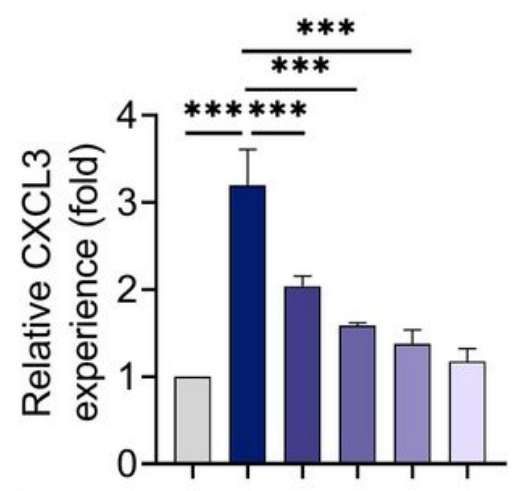

S. aureus - + + + -

B. subtilis H28 - - $10^{7} 10^{8} 10^{9} 10^{9}$

G

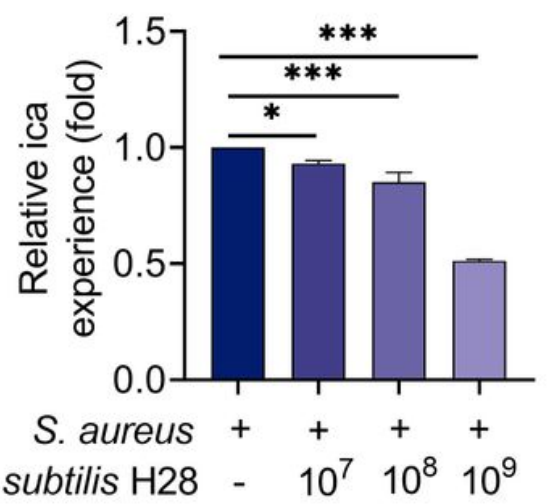

B

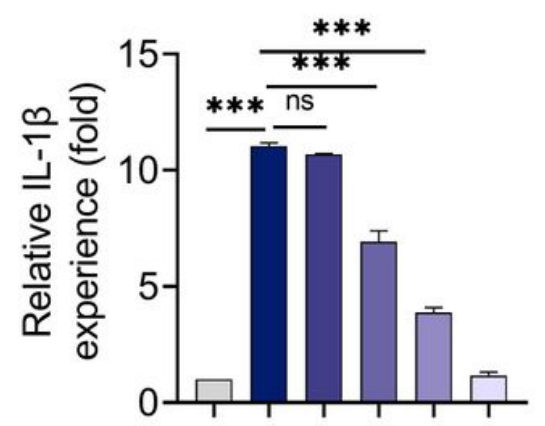

S. aureus - + + + -

B. subtilis $\mathrm{H} 28$ - $\quad 10^{7} 10^{8} 10^{9} 10^{9}$

E

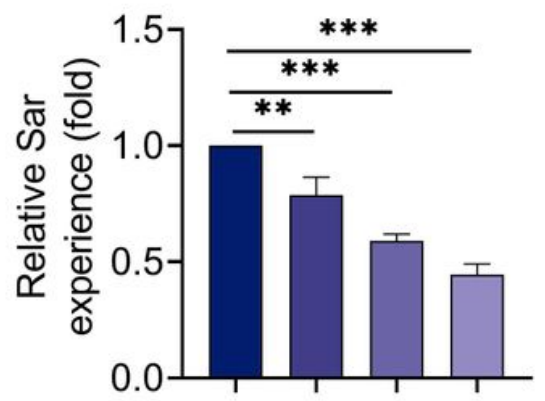

S. aureus ++++

B. subtilis $\mathrm{H} 28$ - $10^{7} 10^{8} 10^{9}$
C

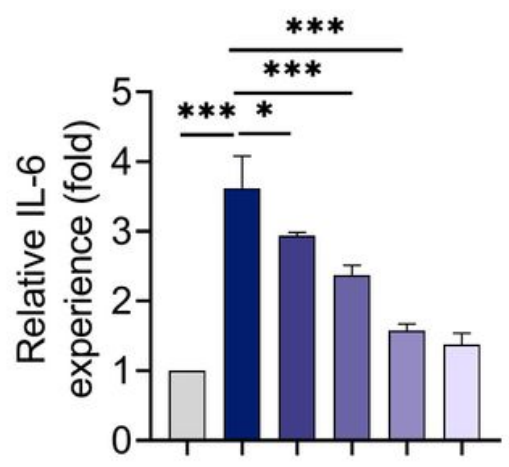

S. aureus - + + + -

B. subtilis $\mathrm{H} 28$ - $\quad 10^{7} 10^{8} 10^{9} 10^{9}$

F

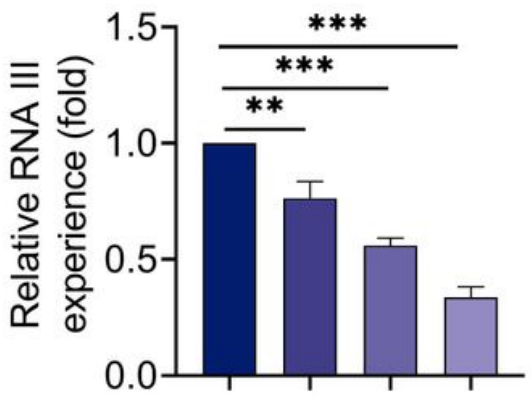

S. aureus ++++

B. subtilis H28 - $10^{7} 10^{8} 10^{9}$

\section{Figure 8}

B. subtilis $\mathrm{H} 28$ inhibited $\mathrm{S}$. aureus-induced inflammatory response and expression of QS genes in mice mammary epithelial cells. (A-C) The TNF- $a$, IL-1 $\beta$ and IL- 6 mRNA levels in mice mammary epithelial cells were identified using qPCR. (D) The CXCL3 mRNA levels in mice mammary epithelial cells were identified using qPCR. (E) Relative expression of the Sar was identified using qPCR. (F) Relative expression of the RNA $\triangle$ was identified using qPCR. (G) Relative expression of the ica was identified using qPCR. The values presented are the mean \pm SEM $(n=3)$. One-way analysis of variance was used for statistical analysis. ${ }^{*} p$ 0.05 and $* p<0.01$ and $* \star \star p ~ \otimes 0.001$ indicate significant differences from each group. ns, no significance. 
A

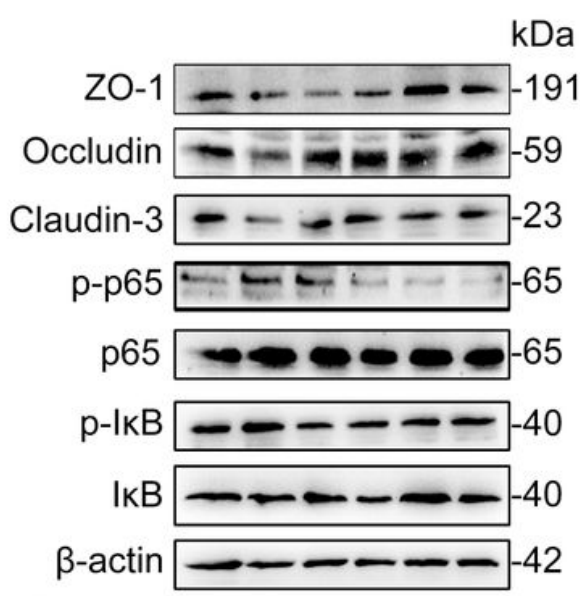

S. aureus - + + + -
B

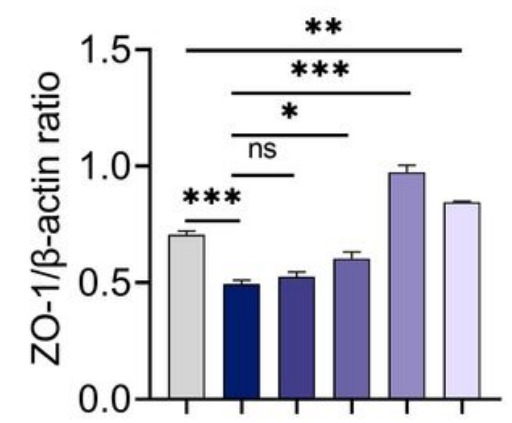

S. aureus - + + + -
C

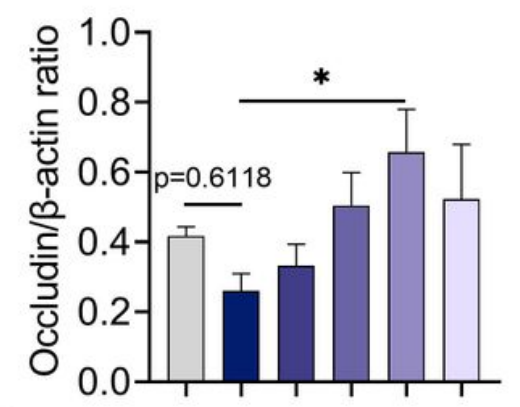

S. aureus - + + + -

B. subtilis $\mathrm{H} 28$ - $-10^{7} 10^{8} 10^{9} 10^{9}$

D

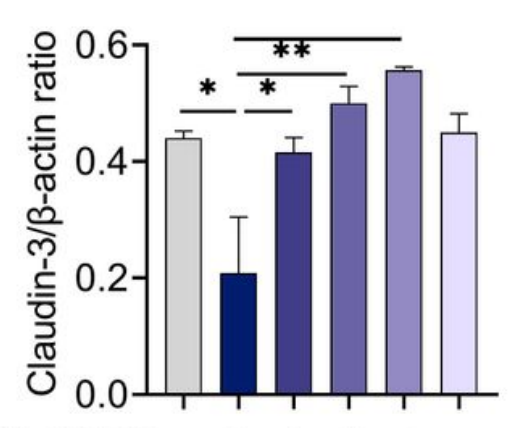

S. aureus - + + + -

B. subtilis $\mathrm{H} 28$ - - $10^{7} 10^{8} 10^{9} 10^{9}$
E

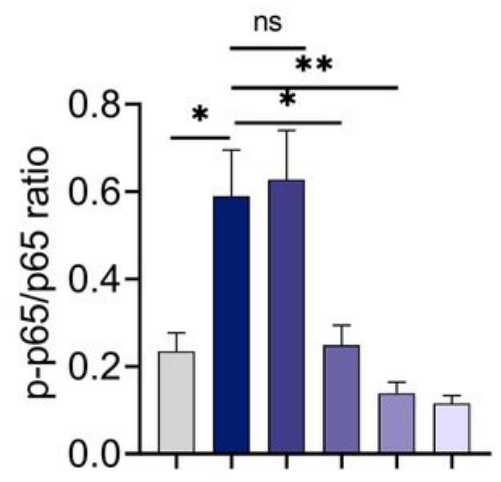

S. aureus - + + + -

$\mathrm{F}$

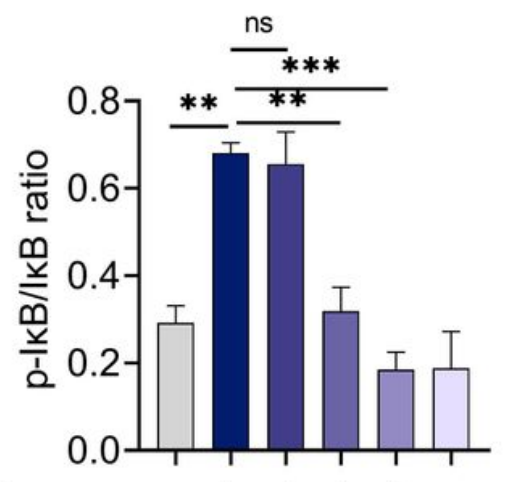

S. aureus - + + + -

B. subtilis $\mathrm{H} 28$ - $\quad 10^{7} 10^{8} 10^{9} 10^{9}$

B. subtilis $\mathrm{H} 28$ - - $10^{7} 10^{8} 10^{9} 10^{9}$

\section{Figure 9}

B. subtilis $\mathrm{H} 28$ increases the tight junction proteins and limits NF-KB activation in mice mammary epithelial cells. Effect of B. subtilis $\mathrm{H} 28$ on the expression of NF-KB pathways were induced by $\mathrm{S}$. aureus. All protein samples were analyzed by Western blot with specific antibodies囚and $\beta$-actin was used as a control. (A) Protein strips. (B) ZO-1/actin ratio (C) Occludin/actin ratio. (D) Claudin-3/actin ratio. (E) pp65/p65 ratio. (F) p- IKB/ IKB ratio. The values presented are the means \pm SEM $(n=3-4)$. One-way analysis of variance was used for statistical analysis. ${ }^{*} p<0.05$ and ${ }^{*} p<0.01$ and ${ }^{* *} \mathrm{p} \otimes 0.001$. ns, no significance. 